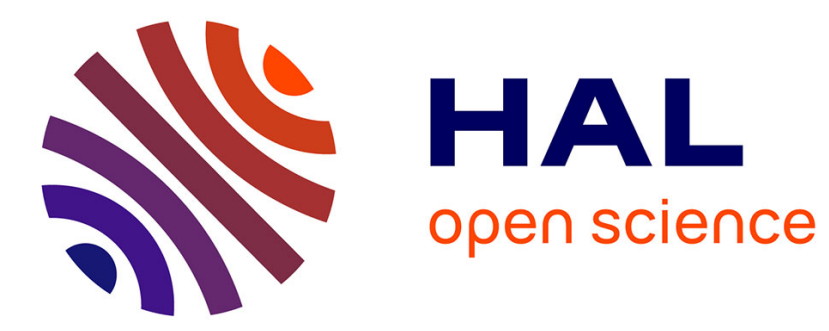

\title{
Photoacoustic determination of energy content and quantum yields of formation of transient states
}

\author{
G. Bilmes, D. Murgida, R. Erra-Balsells
}

\section{To cite this version:}

G. Bilmes, D. Murgida, R. Erra-Balsells. Photoacoustic determination of energy content and quantum yields of formation of transient states. Journal de Physique IV Proceedings, 1994, 04 (C7), pp.C7417-C7-420. 10.1051/.jp4:1994798 . jpa-00253329

\section{HAL Id: jpa-00253329 https://hal.science/jpa-00253329}

Submitted on 1 Jan 1994

HAL is a multi-disciplinary open access archive for the deposit and dissemination of scientific research documents, whether they are published or not. The documents may come from teaching and research institutions in France or abroad, or from public or private research centers.
L'archive ouverte pluridisciplinaire HAL, est destinée au dépôt et à la diffusion de documents scientifiques de niveau recherche, publiés ou non, émanant des établissements d'enseignement et de recherche français ou étrangers, des laboratoires publics ou privés. 


\title{
Photoacoustic determination of energy content and quantum yields of formation of transient states
}

\author{
G.M. Bilmes, D.H. Murgida* and R. Erra-Balsells* \\ Centro de Investigaciones Opticas-CIOp (CONICET-CIC), Casilla de Correo 124, 1900 La Plata, \\ Argentina \\ * Departamento de Quimica Organica, FCEyN-UBA, Ciudad Universitaria Pab. II, 1428 Buenos Aires, \\ Argentina
}

\begin{abstract}
Pulsed laser photoacoustic measurements were used to determine the energy content of the photoisomer of the cyanine dye DTCI and quantum yields of formation of triplet states of purinic compounds.
\end{abstract}

\section{INTRODUCTION}

The measurement of the heat produced in a medium following absorption of a laser pulse can provide kinetic and spectroscopic information of metastable species[1].

In this work the energy content of the photoisomer of the polimethine dye DTCI and quantum yields of formation of triplet states and oxigen quenching effect of purine compounds where determined using pulsed laser induced photoacoustic measurements

Some of the purinic derivatives studied are alkaloids, present in vegetals and commonly used in pharmacology and food technology. Cyanine dyes are very well known as laser media and in modelocking techniques. Both types of molecules are useful as model compounds for photochemical and photophysical studies of biological systems.

As other cyanines dyes, excitation of the first excited singlet state of DTCI produces a short lived photoisomer (lifetime $=10 \mathrm{~ms}$ ) with optical properties similar to those of the stable form, i.e., a strong overlapping of the absorption spectra of both species ${ }^{[2]}$.

In all the purine derivatives studied there are no appreciable fluorescence at room temperature under open atmosphere, in acetonitrile solution ( $\Phi_{\mathrm{f}}<10^{-3}$, naphthalene as fluorescence reference), although some of them showed fluorescence in ethanol solution.

\section{EXPERIMENTAL}

The excitation sources employed in our experiments was a Rhodamine $6 \mathrm{G}$ flash-lamp-pumped dye laser (Chromatix CMX-4) ( $\mu$ s pulses) and a Nd-YAG pulsed laser, operating in the fourth harmonic at $266 \mathrm{~nm}$ (ns pulses). The heat dissipated by the samples, within the time resolution of the experiment 
(ca. $1 \mu \mathrm{s})$, was monitored with a ceramic piezoelectric detector $(4 \times 4 \mathrm{~mm})$ attached to the rear wall of the cell, a normal spectrophotometric $1 \times 1 \mathrm{~cm}$ quartz cuvette.

\section{RESULTS AND DISCUSSION}

After the absorption of the laser pulse, different processes may take place. Equation 1, derived from simple energy balance considerations can be used [1] :

$$
E a=\Phi_{f} E_{f}+\alpha E a+\Phi_{s t} E_{s t}
$$

$\mathrm{Ea}$ is the absorbed molar energy. The first term is the energy dissipated as fluorescence $\left(\Phi_{\mathrm{f}}\right.$ is the fluorescence quantum yield and $E_{f}$ the molar energy of the fluorescing state); $\alpha$ is the fraction of energy deposited in the medium as prompt heat, within the time resolution of the experiment. The third term is the energy stored by species living longer than the heat-integration time; $\Phi_{\mathrm{st}}$ is the quantum yield of formation and $E_{\mathrm{st}}$ the molar energy content of the species formed, i.e., photoisomer for the case of DTCI and triplet states for purine compounds.

The total energy stored $\Phi_{\mathrm{st}} E_{\mathrm{st}}$ can be calculated measuring $\alpha$ and knowing the light emission properties of the sample. Provided one of the terms of the product $\Phi_{\mathrm{st}} \mathrm{E}_{\mathrm{st}}$ is known, the other can be derived.

As is well known the energy-normalized amplitude of the first acoustic signal (H/E) is given by

$$
H / E=K \alpha\left(1-10^{-A}\right)
$$

were $k$ is a constant containing the thermoelastic properties of the solution and instrumental factors and $A$ the absorbance of the sample (S). Using calorimetric references (R), $\alpha$ can be determined for each compound from measurements of $\mathrm{H} / \mathrm{E}$, performed in the same experimental conditions, for sample and reference: $(H / E)_{S} /(H / E)_{R}=\alpha$ if $\alpha_{R}=1$.

In our case $\alpha$ was determined from the slopes of linear plots of $H$ vs $E$ for sample and reference at different absorbances.

\subsection{Energy content of DTCI photoisomer}

For the energy content determination of the photoisomer of DTCI in ethanol, $\lambda=577 \mathrm{~nm}$ was used for excitation. At this wavelength the relation between the cross section of both isomers is maxima and the absorption of the photoisomer can be neglected. A value $\alpha=0.87$ was determined using iodide as reference. From eq. 1 and taking into account from literature [3] that $\Phi_{\mathrm{f}}=0.07, \Phi_{\mathrm{st}}=0.72-0.95$, and $\lambda_{f}=580 \mathrm{~nm}$, a value $E_{\mathrm{st}}=0.16+0.16 \mathrm{eV}$ results for the molar energy content of the photoisomer. 


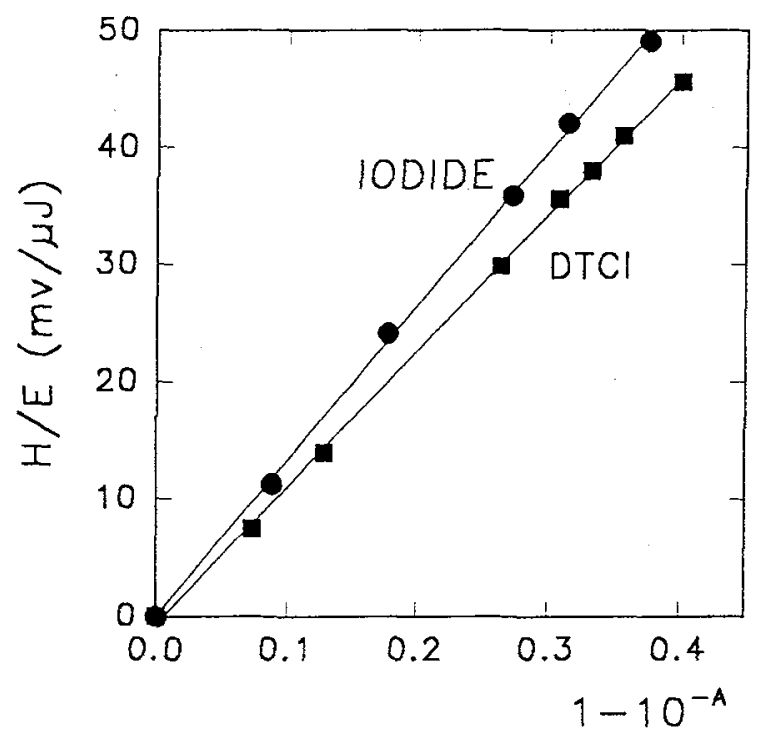

Figure 1 - Normalized signal H/E vs fraction of absorbed energy for sample and reference

\subsection{Quantum yield of triplet state formation in purines compounds}

The purine compounds studied are: Purine, 6-Methylpurine, Adenine, 6-Chloropurine and 6Methoxypurine.

The determination of quantum yields formation of triplet states of purines were performed at $\lambda=$ $266 \mathrm{~nm}$. 2-Hydroxybenzophenone was used as calorimetric reference (CR). It is interesting to mention that this benzophenone derivative has been described to be used as CR in acetonitrile at $\lambda=355 \mathrm{~nm}$ [4] being used in this work as $\mathrm{CR}$ at $266 \mathrm{~nm}$ for the first time.

In our experimental conditions we observed that the $\alpha$ values of all the purinic derivatives studied obtained from experiments ran in air saturated solutions, in acetonitrile, are equal to 2Hydroxybenzophenone value, within experimental error. Thus, these compounds may be used as calorimetric references at $\lambda=266 \mathrm{~nm}$.

A different optoacoustic behaviour was observed for Purine and 6-Methylpurine in nitrogen saturated solutions. As an example, Purine behaviour is shown in Figure 2. Purine in air saturated acetonitrile solution gives a linear relationship $\mathrm{H} / \mathrm{E}$ which slope is modified when the experiments are performed in the presence of $\mathrm{MnCl}_{2}$, Xe and $\mathrm{N}_{2}$. An linear relationship is also observed between $\mathrm{H} / \mathrm{E}$ and (1-10-A) for both purines and 2-Hydroxybenzophenone. The former results mentioned (Figure 2) let us to suppose that the energy storing species is the triplet state because, as it is known oxygen ${ }^{[5]}, \mathrm{Mn}^{+2[6]}$ and $\mathrm{Xe}^{[5,7]}$ have been described as efficient triplet quenchers. 
From equation 1, taking into account that there is negligible fluorescence at room temperature, and that the $E_{s t}$ value can be derived from the phosphorescence spectra ran at low temperature, the quantum yield of triplet formation of Purine and 6-Methylpurine have been estimated as $\Phi_{\text {stPurine }}=0.82$ and $\Phi_{\text {st 6-methylpurine }}=0.89$.

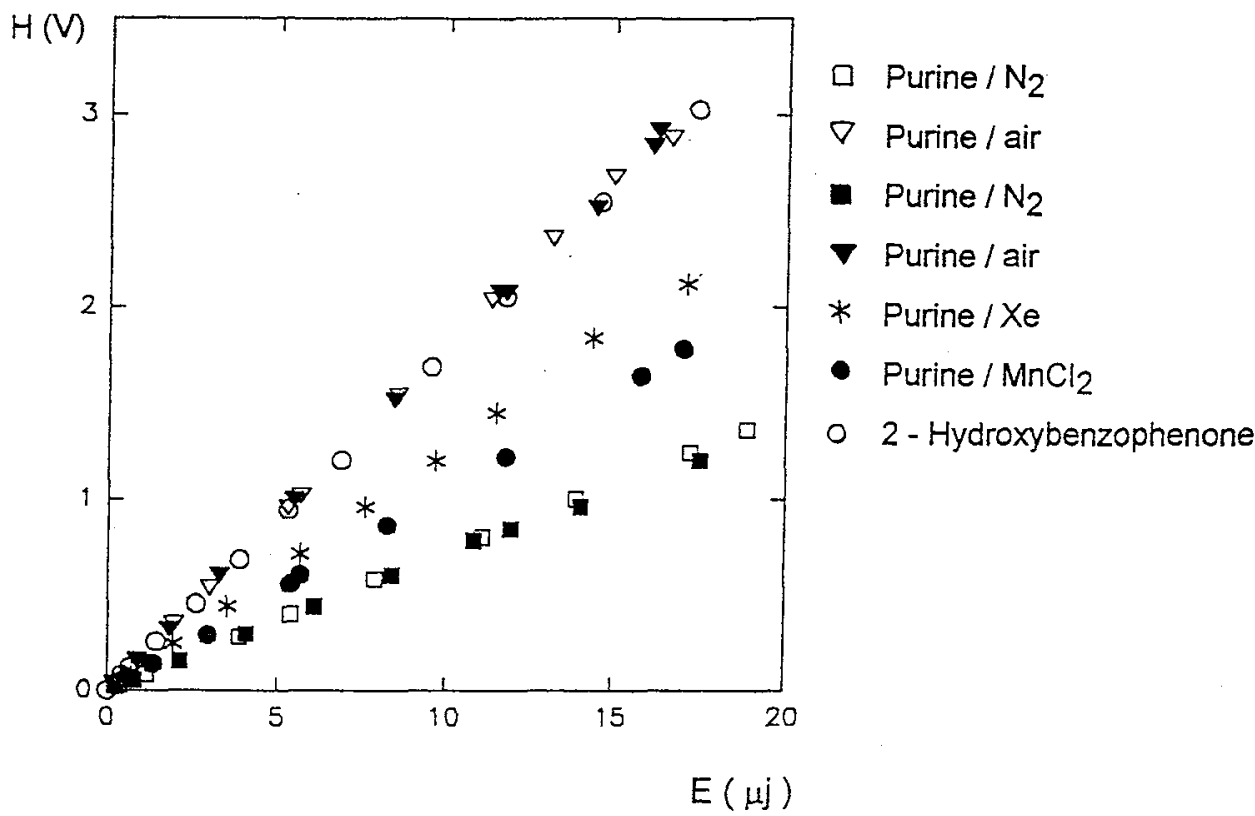

Figure $2-\mathrm{H}$ as function of $\mathrm{E}$ for Purine at different conditions, and reference (2-Hydroxybenzophenone). The absorbance of all solutions was 0.089 . Solvent: acetonitrile.

\section{References}

[1] Braslavsky S.E and Heibel G.E., Chem.Rev. 92 (1992) 1381.

[2] Di Paolo R.E., Scaffardi L., Bilmes G.M. and Duchowicz R., Anales de la Asociacion Fisica Argentina, 3 (1991) 130.

[3] Chibisov A.K., J. Photochem, 6 (1976/77) 199.

[4] Van haver Ph., Viaene L., Van der Auweraer M. and De Schryver F.C., J. Photochem. Photobiol.A: Chem., 63 (1992) 265.

[5] Turro N.J., Modern Molecular Photochemistry,(Benjamin, 1978).

[6] Arce R., Jimenez L.A., Rivera V. and Torres C., Photochem. Photobiol., 32 (1980) 91.

[7] Siegel S. and Judeikis H.S., J. Chem. Phys., 48 (1968) 1613.

* Member of CIC

***Member of CONICET 